\title{
The Effect of Short-Term Administration of Antidiabetic Biguanide Derivatives on the Blood Lactate Levels in Healthy Subjects*
}

\author{
A. Czyżyk, B. Lao, W. Bartosiewicz, Z. Szczepanik, and K. Orłowska \\ Department of Gastrocnterology and Mctabolic Diseases, Medical Academy, Warsaw, Poland
}

Summary. In three groups of healthy subjects (n $=56$ ) changes in blood lactate, pyruvate and bicarbonate concentrations and $\mathrm{pH}$ were determined during three different loading tests. These were an oral ethanol load $(0.5 \mathrm{~g} / \mathrm{kg}$ body $\mathrm{wt})$, an IV fructose load $(1 \mathrm{~g} / \mathrm{kg}$ body wt over $60 \mathrm{~min})$, and a $15 \mathrm{~min}$ submaximal exercise load. The same tests were repeated after administration of biguanides for 3 days in the following doses: phenformin $150 \mathrm{mg}$, buformin $300 \mathrm{mg}$ and metformin $2.55 \mathrm{~g}$ daily. All three derivatives induced a significant rise in blood lactate level as well as a significant increase in blood [lactate]/[pyruvate] ratio in relation to control tests. The differences in the effect of individual biguanides were minimal. It was observed, on the other hand, that increments in blood lactate concentrations depended markedly on the type of load given. The highest rise in blood lactate level was found after fructose loading; in the 60th minute of the test after phenformin it was $1.60 \pm 1.29$ (SD), after buformin $1.32 \pm 0.79$, and after metformin $1.31 \pm 0.64$ $\mathrm{mmol} / \mathrm{l}$. The smallest rise of lactate was observed after oral ethanol loading: in the 1st hour of the test the respective values were $0.41 \pm 0.24,0.52$ \pm 0.18 , and $0.91 \pm 0.86 \mathrm{mmol} / 1$. In the exercise test the highest increment of the blood lactate level was observed $15 \mathrm{~min}$ after the end of the exercise, being $1.06 \pm 0.37,1.21 \pm 0.25$ and $1.26 \pm 0.33 \mathrm{mmol} / \mathrm{l}$, respectively. The results of these investigations show that all three biguanide derivatives used in treatment of diabetes - phenformin, buformin and metformin - are risk factors which may induce lactic acidosis under suitable conditions.

Key words: Biguanides, blood lactate, ethanol, fructose, exercise.

\footnotetext{
* This work was presented in part at $14^{\text {emes }}$ Journćes de Diabétologie de 1'Hôtel-Dieu, May 1973, Paris, and at the 9th Congress of IDF, November 1976, New Delhi
}

Although rises in blood lactate concentration in diabetics treated with biguanide derivatives were reported within a few years of their introduction in the treatment of diabetes $[1,2,3]$ and the first reports of dangerous complications resulting from lactic acidosis in these patients were published at the beginning of the $1960 \mathrm{~s}[4,5]$, only in the last few years has this problem aroused general concern. Lactic acidosis is an uncommon complication of biguanide therapy of diabetes, being very dangerous and often fatal. Most observations on this complication have concerned diabetics treated with phenformin. It has been claimed also that treatment of diabetics with other biguanide derivatives - buformin and metformin - causes no such complication $[8,9]$. Although development of lactic acidosis has been reported recently during treatment with buformin $[10,11]$ and metformin $[12,13]$, the number of such cases so far published is much lower.

In the present investigations we tried to examine this problem by comparing the effects of all three biguanide derivatives (e.g. phenformin, buformin and metformin) on blood lactate levels in healthy subjects submitted to loading tests known to cause hyperlactacidaemia $[1,2,14]$.

\section{Material and Methods}

The studies were carried out in three groups and the following loading tests were done:

\section{Oral Ethanol Load}

Ethanol was administered in a dose of $0.5 \mathrm{~g} / \mathrm{kg}$ of body weight as a $40 \%$ solution. Blood samples were taken in the fasting state and 1,2, 4 and 6 hours after alcohol ingestion. The test was performed in 20 subjects, including 15 men and 5 women aged 
from 24 to 62 years (mean age 36 years) and was repeated in 8 subjects after phenformin administration, in 6 after buformin, and in 6 after metformin.

\section{Intravenous Fructose Load}

Fructose $(20 \mathrm{~g} / 100 \mathrm{ml})$ was given over $60 \mathrm{~min}$ as a continuous intravenous infusion in the total dose of $1 \mathrm{~g} / \mathrm{kg}$ body wt. Blood samples were taken fasting pre-infusion and at intervals of $15 \mathrm{~min}$ for $90 \mathrm{~min}$. The test was carried out in 18 subjects: 8 men and 10 women, 15 of them aged 16-60 years and three over 60 years (mean age 42 years) and was repeated in groups of 6 subjects after administration of phenformin, buformin and metformin.

\section{Exercise Test}

It was performed on a cycle ergometer (Zimmermann, GDR) in 18 subjects: 7 men and 11 women aged 19 to 45 years (mean age 29 years). The mean exercise load was 109.3 watts for men and 78.7. watts for women. The exercise accounted for $50 \%$ of maximum oxygen utilization which was determined earlier from the pulse rate in the steady state during three submaximal exercises of known severity, using Astrand-Ryhming nomogram [15]. The duration of exercise was $15 \mathrm{~min}$. The mean pulse rate during the first exercise was $148 / \mathrm{min}$ in men and $152 / \mathrm{min}$ in women, and during the second exercise the respective rates were $142 / \mathrm{min}$ and $148 / \mathrm{min}$; it was thus somewhat lower (not significantly) during the second test. Blood samples for determinations were obtained from fasting subjects 10 and $15 \mathrm{~min}$ after the beginning of exercise (steady state) and then twice at an interval of $15 \mathrm{~min}$ and twice at an interval of $30 \mathrm{~min}$. The second exercise load was repeated in groups of 6 subjects after administration of phenformin, buformin and metformin.

In all, the determinations were performed in 56 healthy non-obese subjects, 30 men and 26 women, and in each subject only one double test was carried out, that is before biguanide administration (control test) and after its administration. All persons were volunteers, and were previously informed about the nature and the aim of these investigations. Each biguanide derivative was administered for 3 days in the sustained action form (dragées) in the following daily doses: phenformin $150 \mathrm{mg}$, buformin $300 \mathrm{mg}$, metformin $2.55 \mathrm{~g}$, and on the fourth day, that is on the day of the second test, the daily dose was given one hour before the test in the form of short-action tablets.

The blood samples were obtained after complete rest lasting at least $30 \mathrm{~min}$. For determination of lac- tate and pyruvate free-flowing venous blood was collected into test tubes containing $0.6 \mathrm{M}$ glacial perchloric acid. Blood glucose was determined by the method of King [18], fructose by the method of Roe [19], alcohol, lactate and pyruvate (the latter in exercise tests only) enzymatically (Boehringer), $\mathrm{pH}$ and bicarbonates with the Micro-Astrup apparatus. Since each subject served as his own control the effect of biguanide derivatives on the various blood components was calculated as net increment ( $\mathrm{x}_{\text {after }}$ $-\mathrm{x}_{\text {before }}=\mathrm{d}$ ) and results were assessed using the paired " $t$ " test at the significance level $p<0.05$. For determining the significance of differences in the lactogenic effects of various biguanide derivatives one way analysis of variance was used.

\section{Results}

\section{Oral Ethanol Load}

After oral administration of the test dose of ethanol the highest alcohol concentration in the blood, about $0.6 \mathrm{~g} / 1$, was observed one hour after ingestion. Over the following 5 hours the blood alcohol level decreased gradually to below $0.1 \mathrm{~g} / \mathrm{l}$. The administration of biguanides had no effect on the maximal rise of ethanol concentration in the blood or on the rate of its disappearance. On the other hand, a slight but repeatedly occurring effect of these drugs on blood sugar level was demonstrated: one hour after ethanol ingestion blood glucose concentration rose slightly and previous administration of biguanides prevented this.

In the reported tests a rise in blood lactate level was always observed, reaching a peak value one hour after alcohol ingestion. Hyperlactacidaemia persisted for some period of time, returning to normal gradually within the following 5 hours. After previous administration of biguanide derivatives the rise in blood lactate after ethanol ingestion was significantly higher than in control tests (Table 1). This was particularly evident when the results were calculated as difference of increments in blood lactate after the test dose of ethanol.

The fall in plasma bicarbonate after ethanol ingestion was small and transient and administration of biguanides failed to influence this. The blood $\mathrm{pH}$ was not significantly changed either in control tests or in tests after administration of biguanide derivatives.

\section{Intravenous Fructose Load}

Following intravenous infusion of fructose the blood fructose level increased on average up to $50 \mathrm{mg} / \mathrm{dl}$ 

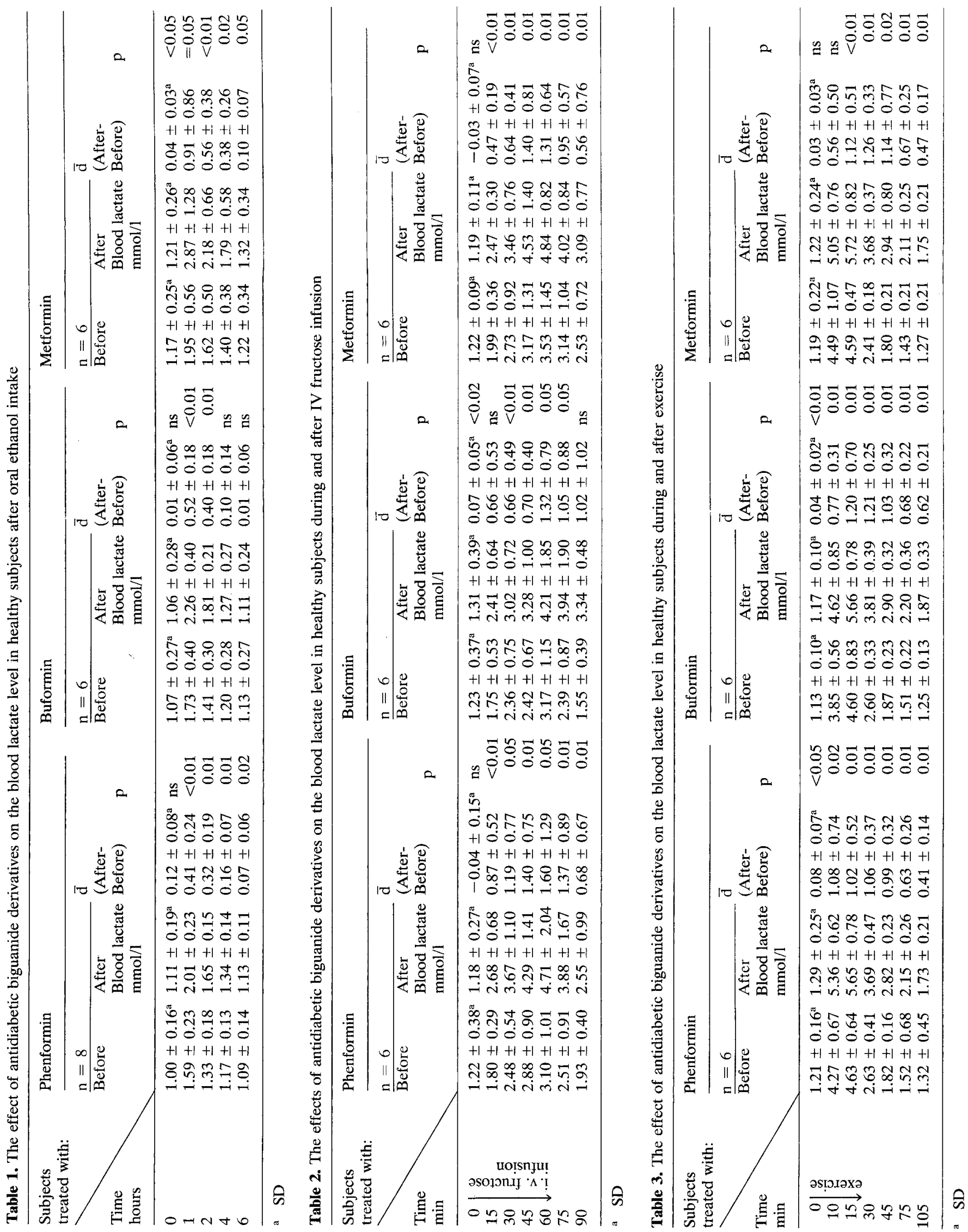
Table 4. Net increments $(\overline{\mathrm{d}} \rightarrow)$ in blood [lactate]/[pyruvate] ratio induced by phenformin, buformin and metformin on fasting, during and after exercise in healthy subjects

\begin{tabular}{|c|c|c|c|c|c|c|c|c|}
\hline $\begin{array}{l}\text { Biguanide } \\
\text { derivative }\end{array}$ & Time & on fasting & $10 \mathrm{~min}$ & $15 \mathrm{~min}^{\mathrm{a}}$ & $30 \mathrm{~min}$ & $45 \mathrm{~min}$ & $75 \mathrm{~min}$ & $105 \mathrm{~min}$ \\
\hline $\begin{array}{l}\text { Phenformin } \\
n=6\end{array}$ & $\begin{array}{l}\bar{d} \rightarrow \\
\mathrm{SD} \\
\mathrm{p}\end{array}$ & $\begin{aligned} & 0.89 \\
\pm & 1.54 \\
\mathrm{~ns} & \end{aligned}$ & $\begin{array}{l}6.15 \\
\pm 3.37 \\
\mathrm{~ns}\end{array}$ & $\begin{array}{r}6.77 \\
\pm 4.11 \\
<0.05\end{array}$ & $\begin{array}{r}9.91 \\
\pm 2.18 \\
<0.01\end{array}$ & $\begin{array}{l}11.14 \\
\pm 2.15 \\
<0.01\end{array}$ & $\begin{array}{r}8.90 \\
\pm 4.64 \\
\text { ns }\end{array}$ & $\begin{array}{r}7.94 \\
\pm 4.08 \\
\mathrm{~ns}\end{array}$ \\
\hline $\begin{array}{l}\text { Buformin } \\
n=6\end{array}$ & $\begin{array}{l}\bar{d} \rightarrow \\
S D \\
p\end{array}$ & $\begin{array}{l}-0.11 \\
\pm 1.10 \\
\mathrm{~ns}\end{array}$ & $\begin{array}{r}5.72 \\
\pm 2.43 \\
<0.02\end{array}$ & $\begin{array}{r}9.47 \\
\pm 6.36 \\
<0.05\end{array}$ & $\begin{array}{r}16.36 \\
\pm 11.41 \\
<0.05\end{array}$ & $\begin{array}{r}15.55 \\
+12.18 \\
<0.05\end{array}$ & $\begin{array}{r}10.23 \\
\pm 6.65 \\
<0.05\end{array}$ & $\begin{array}{r}8.75 \\
\pm 4.82 \\
<0.02\end{array}$ \\
\hline $\begin{array}{l}\text { Metformin } \\
n=6\end{array}$ & $\begin{array}{l}\bar{d} \rightarrow \\
\mathrm{SD} \\
\mathrm{p}\end{array}$ & $\begin{array}{r}0.11 \\
\pm 1.80 \\
\text { ns }\end{array}$ & $\begin{array}{r}6.42 \\
\pm 5.06 \\
\mathrm{~ns}\end{array}$ & $\begin{array}{r}9.50 \\
\pm 2.96 \\
<0.02\end{array}$ & $\begin{array}{r}11.53 \\
\pm 2.30 \\
<0.01\end{array}$ & $\begin{array}{r}12.59 \\
\pm 5.85 \\
<0.01\end{array}$ & $\begin{array}{r}9.36 \\
\pm 4.19 \\
\mathrm{~ns}\end{array}$ & $\begin{array}{r}7.26 \\
\pm 3.72 \\
\mathrm{~ns}\end{array}$ \\
\hline
\end{tabular}

a Termination of exercise

b The differences between the particular biguanide derivatives were not significant at any compared point of observation

Table 5. The effect of short-term administration of antidiabetic biguanide derivatives on the fasting blood lactate level in healthy subjects

\begin{tabular}{|c|c|c|c|c|}
\hline \multirow{2}{*}{$\begin{array}{l}\text { Subjects } \\
\text { treated } \\
\text { with: }\end{array}$} & \multirow[b]{2}{*}{$\mathrm{n}$} & \multicolumn{2}{|c|}{$\begin{array}{l}\text { Fasting blood lactate } \\
\mathrm{mmol} / \mathrm{l}\end{array}$} & \multirow{2}{*}{$\begin{array}{l}\overline{\mathrm{d}} \rightarrow \\
\text { (After- } \\
\text { Before) }\end{array}$} \\
\hline & & Before & After & \\
\hline Phenformin & 20 & $1.13 \pm 0.77^{\mathrm{a}}$ & $1.19 \pm 0.38^{\mathrm{a}}$ & $\left.0.08 \pm 0.09_{1}^{a}\right]$ \\
\hline Buformin & 18 & $1.14 \pm 0.30$ & $1.18 \pm 0.54$ & $0.03 \pm 0.06 \mid p<0.05$ \\
\hline Metformin & 18 & $1.19 \pm 0.17$ & $1.20 \pm 0.20$ & $0.01 \pm 0.05]^{\mathrm{t}}$ \\
\hline
\end{tabular}

a $\mathrm{SD}$

at $15 \mathrm{~min}$ and then it rose more slowly to $80 \mathrm{mg} / \mathrm{dl}$ at the end of the infusion, falling rapidly thereafter. At the same time the blood glucose level increased on the average to $140 \mathrm{mg} / \mathrm{dl}$. Administration of biguanide derivatives had no effect on the blood fructose changes. Similarly, phenformin and metformin failed to modify the blood, glucose curve in these tests. Unexpectedly, after buformin the mean blood glucose curve was significantly below the control from 15 till $75 \mathrm{~min}$ of the test.

The maximum rise in blood lactate occurred usually in the 60th minute of the test and raised values of blood lactate persisted for $30 \mathrm{~min}$ after the end of fructose infusion. After previous administration of biguanides the rise in blood lactate level was significantly higher than in control tests (Table 2).

The greatest decrease of plasma bicarbonate level, on the average to $20 \mathrm{mEq} / \mathrm{l}$, was observed at the end of fructose infusion and it was slightly (not significantly) greater in tests after administration of biguanides. The blood $\mathrm{pH}$ fell significantly to about 7.30 in the 60th minute of the test and biguanides did not increase this.

\section{Exercise Test}

During exercise a slight (but significant) decrease of blood glucose concentration occurred, and it persisted till the end of the test. Biguanides caused no significant modification of the blood glucose curve.

The mean maximum rise in blood lactate concentration occurred at the end of exercise. Levels then decreased but were still elevated above fasting concentration 90 min later. All biguanide derivatives tested caused a significantly higher rise in the lactate level (Table 3) and also a significant rise of blood [lactate]/[pyruvate] ratio (Table 4). Between 10 and $15 \mathrm{~min}$ of the test a significant fall in plasma bicarbonate occurred to a value of $18 \mathrm{mEq} / \mathrm{l}$ and then the base reserve increased. Apart from a slight fall in plasma bicarbonate in the fasting state in one set of determinations, the administration of biguanides had no effect on the base reserve in the exercise test. The blood $\mathrm{pH}$ was not significantly changed in control tests and in tests after previous administrations of biguanide derivatives.

\section{Comparison of Various Biguanide Derivatives on Blood Lactate Concentration}

Table 5 shows that administration of various biguanide derivatives over 3 days caused a very slight rise in fasting lactacidaemia which was, however, significantly higher after phenformin than after buformin or metformin. In the tests, the effect of individual biguanides on blood lactate rise depended to some extent on the type of load used. Thus, the blood lactate levels after fructose load and exercise were significantly higher than after ethanol ingestion. Consequently the increments in blood lactate level after administration of antidiabetic bigua- 
nide derivatives were also higher in the fructose and exercise tests than in the ethanol test. The mean values of maximum increment of blood lactate in the tests after pooling results for all three biguanides were significantly different (the mean maximum blood lactate increment in the first hour of the ethanol test was $0.59 \pm 0.52(\mathrm{SD}) \mathrm{mmol} / \mathrm{l}$, with fructose $1.41 \pm 0.91 \mathrm{mmol} / \mathrm{l}$, while after exercise it was $1.11 \pm 0.55 \mathrm{mmol} / \mathrm{l}$ ).

The lactogenic effect of various antidiabetic biguanide derivatives should be considered separately for each kind of test. A comparison of net increments of lactacidaemia showed that the effects of the biguanides were very similar in the exercise test. In the ethanol test the greatest net increment of blood lactate was observed after metformin (in the 4th and 6th hour of the test the values were significantly higher than after phenformin and buformin).

\section{Discussion}

The mechanism of increased accumulation of lactate in the blood after administration of antidiabetic biguanides has not been elucidated completely. The mechanisms considered are overproduction due to increased rate of anaerobic glycolysis $[18,19]$ as well as underutilization due to inhibition of gluconeogenesis [20] and/or inhibition of lactate oxidation in peripheral tissues [21]. These effects are a common feature of the pharmacological action of all antidiabetic biguanide derivatives, and they were to be expected after administration of various biguanide derivatives [22]. The results of the present investigations confirm these effects in humans. The differences in blood lactate rise and blood [lactate]/ [pyruvate] ratio rise after therapeutic doses of phenformin, buformin and metformin are very small and due probably to differences in the pharmacokinetics of these drugs. It may be concluded, therefore, that these differences are without any practical significance and that in cases with conditions predisposing to hyperlactacidaemia every one of the above mentioned biguanide derivatives could cause fatal lactic acidosis.

The presently reported results stress also the importance of the factor predisposing to development of lactic acidosis in diabetics treated with biguanides. The fructose load and exercise load tests which caused a greater rise in lactacidaemia than oral ethanol loading, induced also a greater increase in lactacidaemia after administration of biguanides. A considerable rise in blood lactate level and blood [lactate]/[pyruvate] ratio after biguanide derivatives in the exercise test deserves attention. Our results differ in this respect from certain earlier reports [23, 24] which may be due to differences in methods.

The investigations on the development of lactic acidosis after phenformin treatment of patients with concomitant renal failure suggested a correlation between the level of phenformin in the blood and the degree of blood lactate rise [25]. However, it has been stressed recently that in some cases phenformin caused development of lactic acidosis despite absence of a predisposing factor and with no increased level of the drug in the blood [26-30]. In this connection it is worth while to emphasize the presence of considerable individual differences observed in our healthy volunteers in their responses to administration of antidiabetic biguanides. In some cases quite unexpectedly high blood lactate rises were found after administration of any of these agents, exceeding blood lactate increments observed on the average in a given group. It may be that this individual predisposition to development of hyperlactacidaemia after administration of antidiabetic biguanides may explain cases in which lactic acidosis developed during diabetes treatment with these agents despite absence of known predisposing factors. Finally it must be emphasized that our studies were performed in normal subjects and one should extrapolate from such data with care. None the less the results are highly suggestive and useful therapeutic guidelines may be derived.

Acknowledgement. We acknowledge gratefully the help of Professor F. Schmidt, M.D. (Boehringer, Mannheim, FRG) who supplied the sets for enzymatic determination of lactate, pyruvate and alcohol in blood, and the assistance of A. Królewski, M. D. (Department of Epidemiology, Medical Academy in Warsaw) in statistical analysis of results.

\section{References}

1. Walker, R. S., Linton, A.L., Thompson, W.S. T.: Mode of action and side effects of phenformin hydrochloride. Br. Med. J. 1960 II, 1567-1569

2. Craig, J., Miller, M., Woodward, H., Meric, E.: Influence of phenylethylbiguanide on lactic, pyruvic and citric acids in diabetic patients. Diabetes 9, 186-193 (1960)

3. Fajans, S.S., Moorhouse, J. A., Doorenbos, H., Louis, L. H., Conn, J. W.: Metabolic effects of phenethylbiguanide in normal subjects and in diabetic patients. Diabetes 9, 194-201 (1960)

4. Gottlieb, A., Duberstein, J., Geller, A.: Phenformin acidosis. N. Engl. J. Med. 287, 806-809 (1962)

5. Tranquada, R.E., Bernstein, S., Martin, H. E.: Irreversible lactic acidosis associated with phenformin therapy. JAMA 184, 37-42 (1963)

6. Oliva, P. B.: Lactic acidosis. Am. J. Med. 48, 209-225 (1970)

7. Dembo, A. J., Marliss, E. B., Halperin, M.L.: Insulin therapy in phenformin-associated lactic acidosis. A case report, biochemical considerations and review of literature. Diabetes 24, 28-35 (1975) 
8. Jahnke, K., Daweke, H., Liebermeister, H., Schilling, G., Grüneklee, D.: Über den Einfluß von Buformin auf das Verhalten von Gewicht und Stoffwechselmetaboliten bei Fettsüchtigen mit und ohne Störung der Glukose-Toleranz. In: K. Oberdisse, H. Daweke, G. Michael (eds.): 2. Internationales Biguanid-Symposium, Düsseldorf 1967, pp. 82-91. Stuttgart: Thieme Verlag 1968

9. Debry, G., Laurent, J.: Acidose lactique et diabète sucré. Helv. Med. Acta 35, 433-447 (1970)

10. Clavadetscher, P., Bischof, P., Wegmann, T.: Laktat-Azidose nach Buformin-Medikation. Dtsch. Med. Wochenschr. 101, 238 (1976)

11. Thimme, W., Buschmann, H.-J., Dissmann, W., Amft, R.: Biguanid-therapie und Lactatacidose. Med. Klin. 71, 1429-33 (1976)

12. Lebacq, E. G., Tirzmalis, A.: Metformin and lactic acidosis. Lancet 1973 I, 314-315

13. Assan, R., Heuclin, Ch., Ganeval, G., Bismuth, Ch., George, J., Girard, J. R.: Metformin-induced lactic acidosis in the presence of acute renal failure. Diabetologia 13, 211-217 (1977)

14. Johnson, H. K., Waterhouse, Ch.: Relationship of alcohol and hyperlactacidemia in diabetic subjects treated with phenformin. Am. J. Med. 45, 98-104 (1968)

15. Astrand, J.: Aerobic work capacity in men and women with special reference to age. Acta Physiol. Scand. [Suppl. 169] 49 (1960)

16. King, E. J.: Microanalysis in Medical Biochemistry. London: J. A. Churchill Ltd. 1947

17. Roe, J.H.: A colorimetric method for the determination of fructose in blood and urine. J. Biol. Chem. 107, 15-22 (1934)

18. Williams, R.H., Tyberghein, J.M., Hyde, P.M., Nielsen, R. L.: Studies related to the hypoglycemic action of phenethylbiguanide. Metabolism 6, 311-319 (1957)

19. Steiner, D.F., Williams, R.H.: Respiratory inhibition and hypoglycemia by biguanides and decamethylenediguanidine. Biochim. Biophys. Acta 30, 329-340 (1958)

20. Altschuld, R. A., Kruger, F.A.: Inhibition of hepatic gluconeogenesis in guinea pig by phenformin. Ann. N. Y. Acad. Sci. 148, 612-622 (1968)
21. Searle, G.L., Siperstein, M.D.: Lactic acidosis associated with phenformin therapy. Evidence that inhibited lactate oxidation is the causative factor. Diabetes 24, 741-745 (1975)

22. Beckmann, R.: Biguanide (Experimenteller Teil). In: (ed.): H. Maske Handbuch der experimentellen Pharmakologie, Vol. 29, pp. 439-596. Berlin, Heidelberg, New York: Springer 1971

23. Shepardson, C.R., Christopher, T.G., Miller, M.: The effect of phenethylbiguanide on blood lactate levels following exercise. J. Lab. Clin. Med. 60, 1018 (1962)

24. Gütler, F., Petersen, B., Kjeldsen, K.: The influence of phenformin on blood lactic acid in normal and diabetic subjects during exercise. Diabetes 12, 420-423 (1963)

25. Assan, R., Heuclin, C., Girard, J.R., Lemaire, F., Attali, J. R.: Phenformin-induced lactic acidosis in diabetic patients. Diabetes 24, 791-800 (1975)

26. Cohen, R.D., Ward, J.D., Brain, A.J.S., Murray, C.R., Savege, T.M., Iles, R. A.: The relation between phenformin therapy and lactic acidosis. Diabetologia 9, 43-46 (1973)

27. Fulop, M., Hobeman, H.D.: Phenformin-associated metabolic acidosis. Diabetes 25, 292-296 (1976)

28. Conlay, L. A., Loewenstein, J.E.: Phenformin and lactic acidosis. JAMA 235, 1575-78 (1976)

29. Conlay, L. A., Matin, S. B., Loewenstein, J.E.: Serum phenformin concentrations in patients with phenformin-associated lactic acidosis. Diabetes 25 (Suppl. 1), 359 (1976)

30. Gale, E.A.M., Tattersall, R.B.: Can phenformin-induced lactic acidosis be prevented? Brit. Med. J. 1976 II, 972-975

Received: January 24, 1977, and in revised form: August 2, 1977

Prof. Artur Czyżyk, M.D.

Department of Gastroenterology and Metabolic Diseases

Medical Academy

ul. Lindleya 4

02-005 Warszawa

Poland 